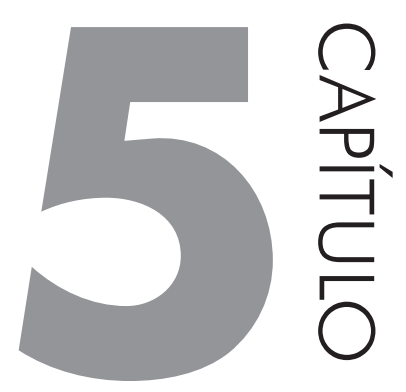

\title{
A VARIAÇÃO DA CONCORDÂNCIA NOMINAL NUM DIALETO RURAL
}

EVANILDA MARINS ALMEIDA ${ }^{1}$

\section{INTRODUÇÃO}

A pesquisa, cujos resultados se discutem, teve por objetivo analisar o comportamento do -s marcador de número em SNs, no âmbito da fala de doze comunidades pesqueiras do Norte do estado do Rio de Janeiro. O corpus foi constituído por SNs elicitados de setenta e dois inquéritos do Arquivo Sonoro do APERJ (Atlas Etnolinguístico do Estado do Rio de Janeiro), ao qual esta pesquisa está vinculada. Os informantes - todos do sexo masculino e analfabetos ou semi-escolarizados - foram distribuídos por três faixas etárias (A - 18 a 35 anos; B - 36 a 55 anos; $\mathrm{C}-$ mais de 56 anos).

Foram analisados 4.784 vocábulos flexionáveis, classificados como marcados e não marcados. A análise de cunho variacionista foi realizada com o auxílio

\footnotetext{
Este artigo consiste no resumo da dissertação de Mestrado A concordância nominal num dialeto rural. Trabalho realizado sob a orientação firme e segura da Professora Silvia Brandão, a quem agradeço pelo incentivo, paciência e compreensão que se transformaram em amizade e que me incentivaram a realizar voos mais altos e fazer escolhas acertadas.
} 
do pacote de programas VARBRUL, em duas etapas. Na primeira, consideraram-se as variáveis posição linear, classe gramatical do vocábulo e função sintática do vocábulo no $\mathrm{SN}$, entre outras. $\mathrm{Na}$ segunda, esses grupos foram substituídos pela variável relação entre os constituintes do $S N$. Tais procedimentos tiveram por objetivo (1) testar o comportamento das variáveis posição linear e classe do vocábulo, consideradas, em alguns trabalhos, condicionantes da marcação de número nos constituintes do $\mathrm{SN}$; (2) verificar se a variável relação entre os elementos do $S N$ daria conta das inter-relações existentes entre as referidas variáveis e (3) estabelecer qual das duas opções de análise se mostraria mais pertinente para a aplicação da regra de cancelamento da marca de número entre os elementos do SN. Os resultados das análises referem-se à não concordância nominal. Como o objetivo da pesquisa é observar as regras que condicionam a norma dos pescadores, justifica-se a opção pelo valor de aplicação não marcação de plural, já que o corpus estudado mostrou maior tendência ao cancelamento.

\section{REVISÃO BIBLIOGRÁFICA}

Apreciaram-se os trabalhos sobre o tema e os que a ele se relacionam. Assim, sintetizam-se observações contidas em gramáticas, nas obras dos dialectólogos brasileiros e em pesquisa no âmbito da Sociolinguística. Cotejaram-se as principais gramáticas publicadas no Brasil, os estudos dialectológicos realizados entre as décadas de 1920 e 1950, assim como os das décadas de 1970 e 1980, realizados por Rodrigues (1974) e Veado (1982), que, utilizando princípios teórico-metodológicos do gerativismo, confirmam as observações dos primeiros dialectólogos. No âmbito da Sociolinguística, sintetizaram-se os trabalhos sobre concordância entre os elementos do SN do Português do Brasil, na variante popular e na variante culta da língua.

\section{ASPECTOS TEÓRICO-METODOLÓGICOS}

Para a realização do estudo da não concordância no dialeto dos pescadores do Norte fluminense, recorreu-se aos pressupostos teórico-metodológicos da Sociolinguística variacionista laboviana, segundo a qual a variação é inerente à língua e não é aleatória. $\mathrm{Na}$ realidade, ela pode ser sistematizada através de regras que condicionam a escolha do falante por uma ou outra forma.

Para compreensão de uma regra variável, devem-se considerar os diversos fatores que possam condicionar a opção do falante por uma determinada variante. Assim, torna-se necessário estabelecer as possíveis variáveis que condicionam a 
regra: as linguísticas (contextos fonológicos, morfossintáticos e/ou discursivos) e as extralinguísticas (aspectos do contexto social). A determinação da influência de cada fator na escolha do falante é possível devido ao método quantitativo de análise, que utiliza o pacote de programas VARBRUL. O tratamento estatístico permite ao pesquisador confirmar as hipóteses inicialmente estabelecidas por meio da observação do comportamento dos dados.

Os grupos de fatores estabelecidos e as hipóteses que conduziram a pesquisa tiveram como base não só outros trabalhos na linha variacionista, mas também a observação dos dados que compõem o corpus da pesquisa.

Entre as variáveis independentes, foram levados em conta dois grupos de fatores extralinguísticos - faixa etária e localidade - e onze, de caráter linguístico: processos morfofonológicos de formação de plural, tonicidade do item singular, classe do vocábulo, função do vocábulo no $S N$, número de vocábulos no $S N$, posição linear, marcas precedentes, número de sílabas no vocábulo, tipo de realização, caracterização do SN e contexto fonológico subsequente. Numa etapa posterior, incluíram-se a variável relação entre os constituintes do $S N$ e a variável auxiliar escolaridade. A variável relação entre os constituintes do SN surgiu da combinação das variáveis classe gramatical, posição linear e função do vocábulo no SN. A variável auxiliar escolaridade ajudou a melhor compreender a atuação dos dois referidos grupos de fatores de cunho extralinguístico.

As variáveis número de vocábulos, número de sílabas no vocábulo, tipos de realização e caracterização do $S N$, consideradas nas primeiras rodadas, foram retiradas da análise pelo fato de serem sistematicamente descartadas pelo programa de análise estatística, mostrando-se irrelevantes para o estudo do fenômeno em questão.

\section{ANÁLISE}

Como já se disse, a análise realizou-se em duas etapas. Na primeira, objetivou-se testar a relevância das variáveis classe gramatical e posição linear do vocábulo no SN. Para isso, consideraram-se essas duas variáveis, além da variável marcas precedentes e função sintática - pela estreita relação dessa variável com a classe gramatical -, entre outras, além das extralinguísticas - localidade e faixa etária. Das diversas rodadas realizadas nessa etapa, a considerada mais produtiva foi a que apresentou input .49 e significância .000. O programa selecionou as variáveis marcas precedentes, processos morfofonológicos de formação de plural, classe gramatical, faixa etária e localidade, descartando função sintática, posição linear e contexto fonológico subsequente. 
Para a testagem das variáveis classe gramatical e posição linear, cruzaram-se, com o auxílio do programa CROSSTAB, as variáveis classe gramatical e posição linear, posição linear e marcas precedentes, classe gramatical e marcas precedentes. Os resultados dos cruzamentos mostraram que: os elementos que ocupam a primeira posição apresentam marca de número; a presença de marca semântica ou formal no elemento anterior favorece o cancelamento da marca de plural no elemento analisado, assim como a presença simultânea de marca formal e semântica. Quanto ao cruzamento das variáveis classe e posição, não é possível estabelecer um paralelo entre posição, classe e cancelamento, visto que determinadas classes não seguem uma regra comum em consequência da mobilidade que apresentam na estrutura do $\mathrm{SN}$, à esquerda e/ou à direita do núcleo. Nos dados da pesquisa de Scherre em relação às variáveis classe e posição, também é possível observar que a primeira posição desfavorece o cancelamento da marca de número.

$\mathrm{Na}$ segunda etapa da análise, o programa selecionou os seguintes grupos de fatores: relação entre os constituintes do $S N$, marcas precedentes, processos morfofonológicos de formação de plural, tonicidade do item singular, faixa etária e localidade. A variável contexto fonológico subsequente foi sistematicamente descartada pelo programa.

Os resultados da segunda etapa confirmam a relevância da variável relação entre os constituintes do $S N$, pois ela mostra a distribuição dos elementos não nucleares em relação ao centro do SN, em função da posição (conforme a tabela e o gráfico a seguir).

Tabela 1 Índices referentes à variável relação entre os constituintes do SN. (Valor de aplicação: cancelamento).

\begin{tabular}{|l|c|c|c|c|}
\hline \multicolumn{1}{|c|}{ RELAÇão ENTRE OS CONSTITUINTES DO SN } & OCO. & $\%$ & P. R.N.1 & P. R.N.S \\
\hline Elem. nuclear na 1a posição & $1 / 19$ & $5 \%$ & .06 & .21 \\
\hline Elem. nuclear na 2a posição & $2331 / 2670$ & $87 \%$ & .88 & .65 \\
\hline Elem. nuclear na 3a posição & $150 / 175$ & $86 \%$ & .87 & .49 \\
\hline $\begin{array}{l}\text { Elem. não nuclear anteposto ao núcleo } \\
\text { na 1a posição }\end{array}$ & $49 / 1707$ & $3 \%$ & .03 & .27 \\
\hline $\begin{array}{l}\text { Elem. não nuclear anteposto ao núcleo } \\
\text { na 2a posição }\end{array}$ & $8 / 57$ & $14 \%$ & .15 & .04 \\
\hline Elem. não nuclear posposto ao núcleo & $131 / 156$ & $84 \%$ & .85 & .79 \\
\hline
\end{tabular}




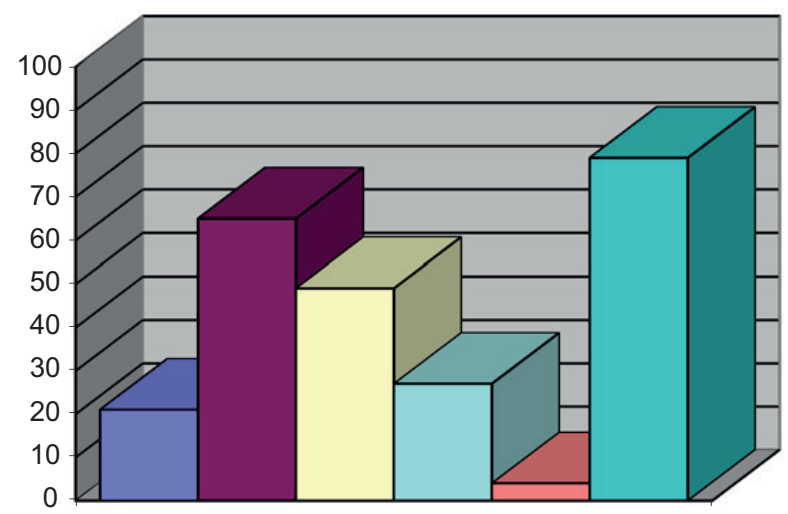

口 Elem. nuclear. 1a.pos.

- Elem. nuclear. 2a. pos.

口 Elem.nuclear 3a. pos.

¿ Elem. ant. ao núcleo, 1a. posição

口 Elem. ant. ao núcleo, 2a. posição

口 Elem. posposto ao núcleo

Gráfico 1 Pesos relativos referentes à variável relação entre os constituintes do SN, (Valor de aplicação: cancelamento).

Desse modo, é possível perceber que os elementos pospostos ao núcleo são os que mais favorecem o cancelamento da marca de número, enquanto os elementos pré-nucleares são os que mais detêm essa marca. Já o elemento nuclear será mais ou menos marcado, de acordo com a posição que ocupar no SN.

O controle da variável marcas precedentes objetivou verificar se, no dialeto dos pescadores, estaria ocorrendo a tendência à eliminação da redundância que caracteriza a flexão nominal do Português ou se estaria agindo o Princípio do Paralelismo Formal, segundo o qual “marcas levam a marcas e zeros levam a zeros”. De acordo com tal princípio, no nível do SN, a marca de plural num dos constituintes levaria à marca no constituinte subsequente e a ausência de marca no primeiro constituinte levaria à ausência de marca no constituinte seguinte.

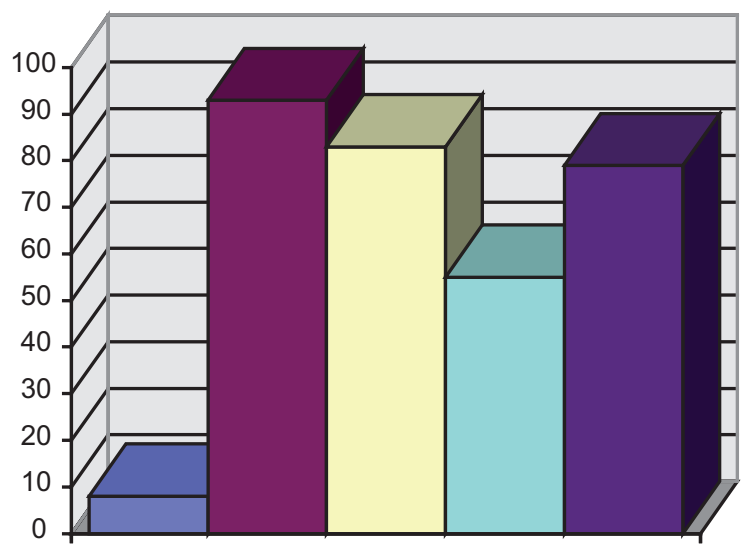

Aus. de elem. ant.

Pres. de marca formal e semt.

口 Pres. de marca semt.

口 Ausência de marca imedt. precedente

- Presença de marca formal imedt. precedente

Gráfico 2 Pesos relativos referentes à variável marcas precedentes. (Valor de aplicação: cancelamento). 
Tabela 2 Índices referentes à variável marcas precedentes. (Valor de aplicação: cancelamento).

\begin{tabular}{|l|c|c|c|c|}
\hline \multicolumn{1}{|c|}{ MARCAS PRECEDENTES } & 0Co. & $\%$ & P. R.N.1 & P. R.N.S. \\
\hline Presença de marca imediatamente precedente & $1355 / 1625$ & $83 \%$ & .85 & .79 \\
\hline Ausência de elemento anterior & $49 / 1724$ & $03 \%$ & .03 & .08 \\
\hline Presença simultânea de marca formal e semântica & $125 / 136$ & $92 \%$ & .93 & .93 \\
\hline Presença de marca semântica (numeral) & $1032 / 1152$ & $90 \%$ & .91 & .83 \\
\hline Ausência de marca imediatamente precedente & $109 / 147$ & $74 \%$ & .76 & .55 \\
\hline
\end{tabular}

A variável marcas precedentes mostrou que no corpus explorado, formado majoritariamente por $\mathrm{SNs}$ de dois elementos, parece estar agindo o princípio da economia linguística. No subcorpus formado por SNs de três e quatro elementos, percebeu-se que, no que se refere aos elementos antepostos, a marca de plural no primeiro elemento propicia a marcação no elemento seguinte (os outros peixe), (todos os bagre), porém essa marca não chega ao núcleo, ou seja, o Paralelismo Formal funciona no âmbito dos determinantes pré-nucleares, mas não no âmbito do determinante, núcleo e modificador (os pescador velho), (os meus irmão tudo). O elemento posposto comporta-se da maneira esperada, ou seja, apresenta alto índice de cancelamento (os barco meu), (os pescador tudo). Ressalte-se, também, a considerável ocorrência de numerais antepostos ao núcleo, o que inibe a marcação de plural no elemento nuclear (os meus três barco), (os três peixe). Tal fato ressalta a influência do numeral no cancelamento da marca de número no elemento a ele anteposto, conforme gráfico a seguir.

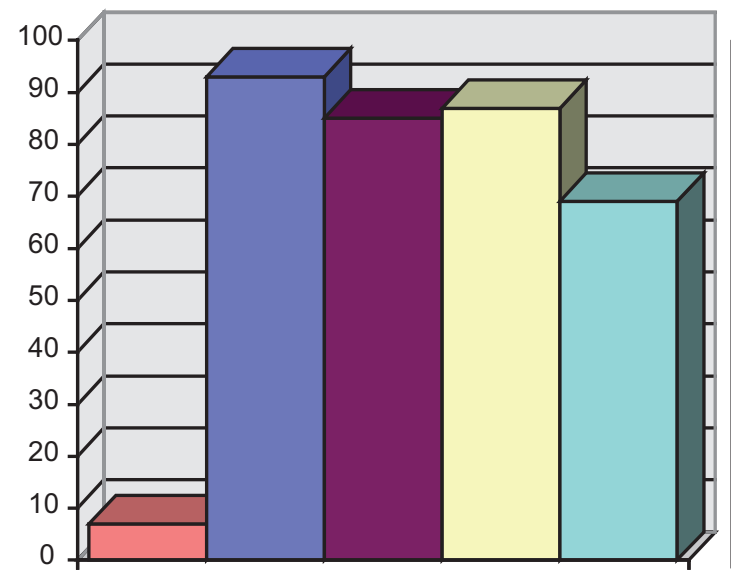

口 Aus. de elem. ant.

Pres. de marca formal e semt.

Pres. de marca semt.

口 Ausência de marca imedt. precedente

$\square$ Presença de marca formal imedt. precedente

Gráfico 3 Pesos relativos referentes à variável marcas precedentes nos SNs de três e quatro elementos. (Valor de aplicação: cancelamento). 
O controle da variável processos morfofonológicos de formação de plural objetivou verificar se, no dialeto dos pescadores do Norte fluminense, estaria agindo o Princípio da Saliência Fônica, que consiste no fato de as formas de plural mais diferenciadas das de singular serem mais perceptíveis, mais salientes e, por isso, mais propícias à flexão de número do que as formas menos salientes.

Os resultados mostram que os itens terminados em vogal são os que apresentam maior índice de cancelamento da marca de plural, seguido dos itens com marca dupla de plural; os itens terminados em /S/ são os que apresentam menor índice de cancelamento.

O gráfico mostra a escala de saliência fônica dos itens que mais favorecem o cancelamento da marca de número. O quadro mostra, ainda, comparativamente o nível de cancelamento em relação à saliência fônica nos dois corpora (ALMEIDA, 1997; SCHERRE, 1988).

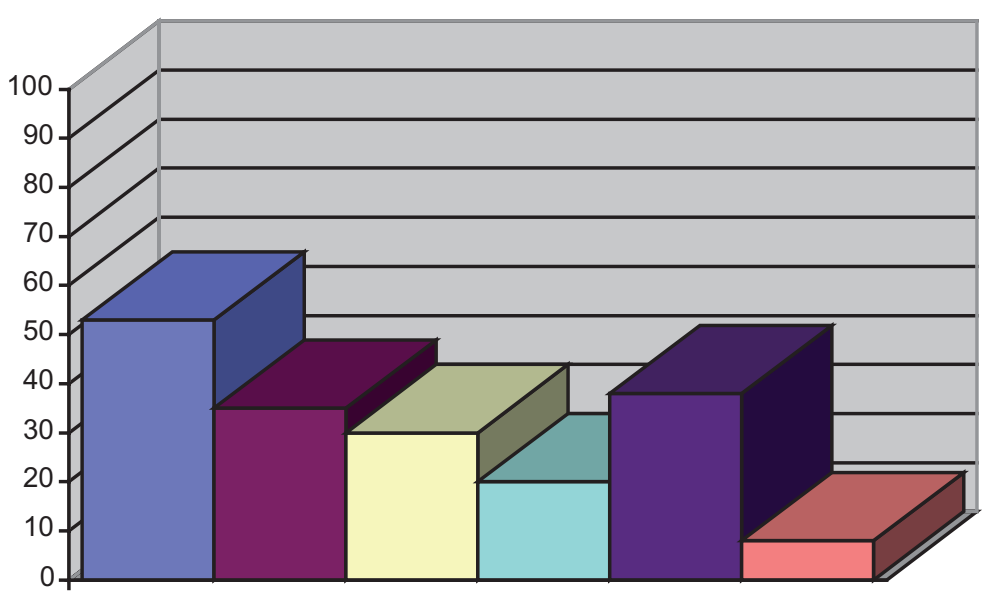

口 Itens terminados em vogal

口 Itens terminados em -ão

口 Itens terminados em /R/

口 Itens terminados em $-1$

Marca dupla de plural

口 Itens terminados em /S/

Gráfico 4 Pesos relativos referentes à variável processos morfofonológicos de formação de plural - incluindo todos os dados. (Valor de aplicação: cancelamento). 
Tabela 3 Comparação dos índices percentuais obtidos por ALMEIDA (1997) aos de SCHERRE (1988). (Valor de aplicação: cancelamento)².

\begin{tabular}{|l|c|c|}
\hline \multicolumn{1}{|c|}{$\begin{array}{c}\text { PROCESSOS DE FORMAÇÃo } \\
\text { DE PLURAL }\end{array}$} & $\begin{array}{c}\text { RESULTADOS DE SCHERRE } \\
\mathbf{( 1 9 8 8 )}\end{array}$ & $\begin{array}{c}\text { RESULTADOS DE ALMEIDA } \\
\mathbf{( 1 9 9 7 )}\end{array}$ \\
\hline Itens terminados em vogal & $67 \%$ & $91 \%$ \\
\hline Itens terminados em -ão & $28 \%$ & $65 \%$ \\
\hline Itens terminados em /R/ & $18 \%$ & $58 \%$ \\
\hline Itens terminados em -I & $30 \%$ & $58 \%$ \\
\hline Itens terminados em /S/ & $22 \%$ & $35 \%$ \\
\hline Marca dupla de plural & $12 \%$ & $83 \%$ \\
\hline
\end{tabular}

Tabela 4 Quadro comparativo do nível de cancelamento em relação à saliência fônica em dois corpora (Valor de aplicação: cancelamento).

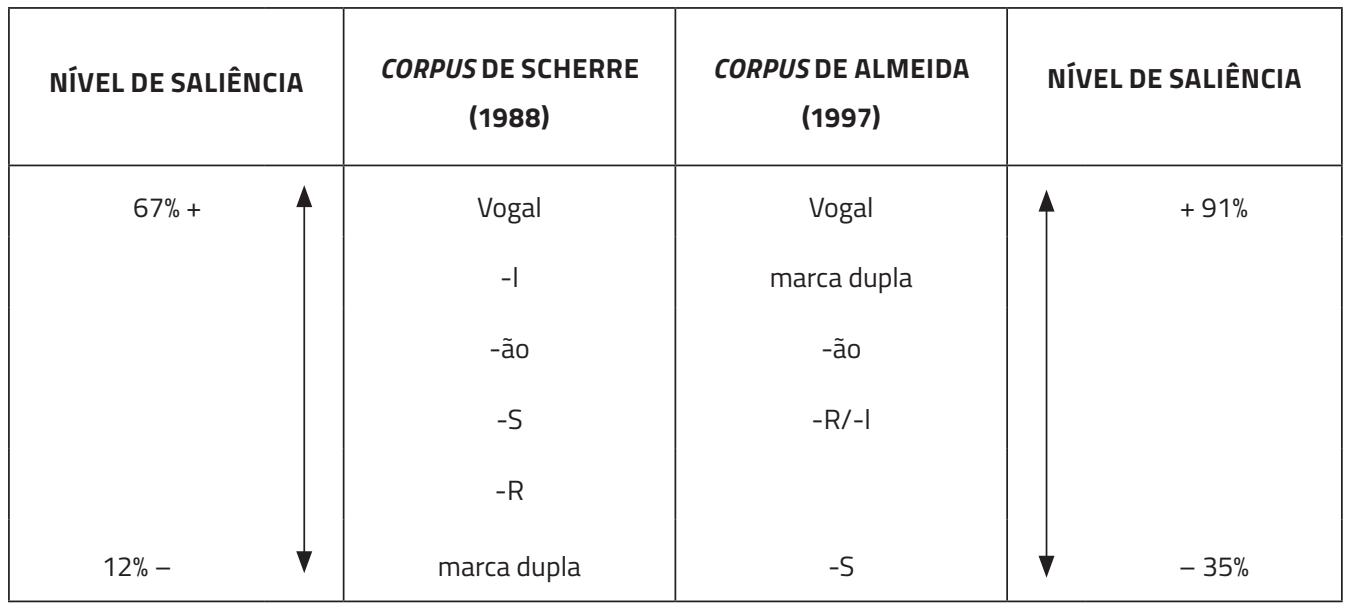

Comparando-se os índices percentuais obtidos no presente estudo aos de Scherre (conferir Tabela 3), observa-se que: (1) há, no corpus de Almeida, maior tendência ao cancelamento em todos os contextos, do que no corpus de Scherre; (2) os itens que mais favorecem o apagamento da marca, nas duas pesquisas, são os que terminam em vogal; (3) dentre os itens com maior diferenciação fônica

2 A Tabela 3 foi organizada, no que se refere aos dados de Scherre (1988), com base nos índices percentuais de seus resultados adaptados para o valor de aplicação igual a cancelamento. 
entre as formas singular e plural, os menos sujeitos ao cancelamento no corpus de Scherre são os que apresentam o segundo índice de apagamento mais representativo no corpus de Almeida (71\% de diferença); (4) enquanto nos dados de Almeida os itens mais marcados são os terminados em /S/, nos de Scherre isso ocorre com aqueles que apresentam marca dupla de plural; (5) os itens terminados em -ão, assim como os terminados em $-\mathrm{l}$ e / R/ apresentam comportamento bem distinto nos dois corpora.

Com o controle da variável tonicidade do item singular, assim como da variável processos morfofonológicos de formação do plural, objetivou-se verificar se, no dialeto dos pescadores, estaria agindo o Princípio da Saliência Fônica. Os resultados mostraram que, conforme o esperado, os itens proparoxítonos são os que mais favorecem o cancelamento da marca de plural e os que menos favorecem são os itens oxítonos e os monossílabos tônicos. As variáveis extralinguísticas apresentaram comportamento instável. O controle da variável faixa etária dos informantes destinou-se a observar o grau de conservadorismo e/ou inovação na fala dos pescadores e, ainda, se haveria uma tendência à mudança linguística em relação ao fenômeno em estudo.

Os resultados da variável faixa etária (conforme a tabela) contrariaram a hipótese inicial deste trabalho de que os falantes mais velhos teriam comportamento linguístico conservador, de maior realização da marca, em oposição ao comportamento inovador, de cancelamento da marca, dos mais jovens. Contrariamente, os resultados mostram que os informantes mais jovens apresentam uma discreta tendência à concordância e os mais velhos, à não concordância. Uma primeira análise indicaria que, no dialeto dos pescadores, há uma tendência a um sistema de concordância.

Tabela 5 Índices referentes ao amalgamento da variável faixa etária e da variável auxiliar escolaridade (Valor de aplicação: cancelamento).

\begin{tabular}{|l|c|c|c|c|}
\multicolumn{1}{|c|}{$\begin{array}{c}\text { FAIXA } \\
\text { ESCOLARIDADE }\end{array}$} & OCO & $\%$ & P. R.N.1 & P. R.N.S \\
\hline A analfabeta & $103 / 198$ & $52 \%$ & .46 & .62 \\
\hline A escolarizada & $689 / 1361$ & $51 \%$ & .45 & .36 \\
\hline B analfabeta & $373 / 647$ & $58 \%$ & .52 & .55 \\
\hline B escolarizada & $525 / 904$ & $58 \%$ & .52 & .56 \\
\hline C analfabeta & $637 / 1061$ & $60 \%$ & .54 & .59 \\
\hline C escolarizada & $343 / 613$ & $56 \%$ & .50 & .49 \\
\hline
\end{tabular}




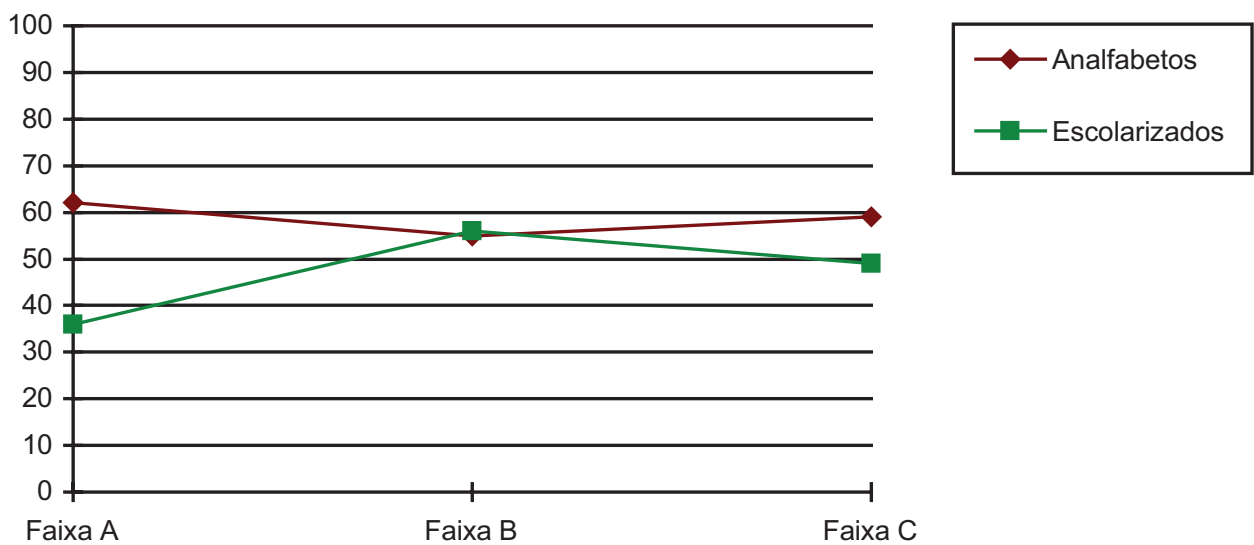

Gráfico 5 Índices referentes ao grau de cancelamento da marca de número por faixa etária e escolaridade.

Procurando-se compreender melhor o comportamento da variável, observaram-se os resultados da faixa etária e localidade. Em termos percentuais, não há, no comportamento linguístico dos informantes das faixas A, B e C de cada localidade, uma regularidade em relação ao cancelamento da marca de número. Comparando-se a análise geral dos dados à que se efetuou por localidade, observa-se que o maior índice de cancelamento na faixa $\mathrm{C}$ não ocorre em todas as localidades, da mesma forma que a faixa A não apresenta regularmente os menores índices de cancelamento. Tal irregularidade demonstrou que algo mais deveria estar interferindo na opção dos falantes, provavelmente o fato de uns serem escolarizados e outros não. Verificou-se haver mais informantes escolarizados na faixa $\mathrm{A}$ (21/24); na faixa C, há o dobro de falantes analfabetos (16/24) e, na faixa B, um equilíbrio (10/14).

Com o objetivo de se investigar mais detalhadamente a influência da escolaridade no comportamento linguístico dos falantes, nas diferentes faixas etárias, amalgamaram-se as variáveis faixa etária e escolaridade.

Os resultados referentes ao amalgamento das duas variáveis mostraram que é na faixa A que se encontram os menores e maiores pesos relativos de cancelamento da marca, para respectivamente os escolarizados e para os analfabetos; os informantes analfabetos e alfabetizados da faixa $\mathrm{B}$ apresentam comportamento semelhante, e os falantes analfabetos da faixa $\mathrm{C}$ apresentam maior tendência ao cancelamento.

Quanto aos informantes da faixa A, pode estar sendo decisivo para a seleção da variável tanto a escolaridade quanto outros fatores relativos à interação com falantes de diferentes localidades e níveis sociais. 
Os resultados mostram uma tendência estável na fala dos analfabetos, cujos índices variam de .56 a .62. Em relação aos escolarizados, observa-se o inverso, ou seja, variação tendente ao não cancelamento, com índice entre .36 e .55 .

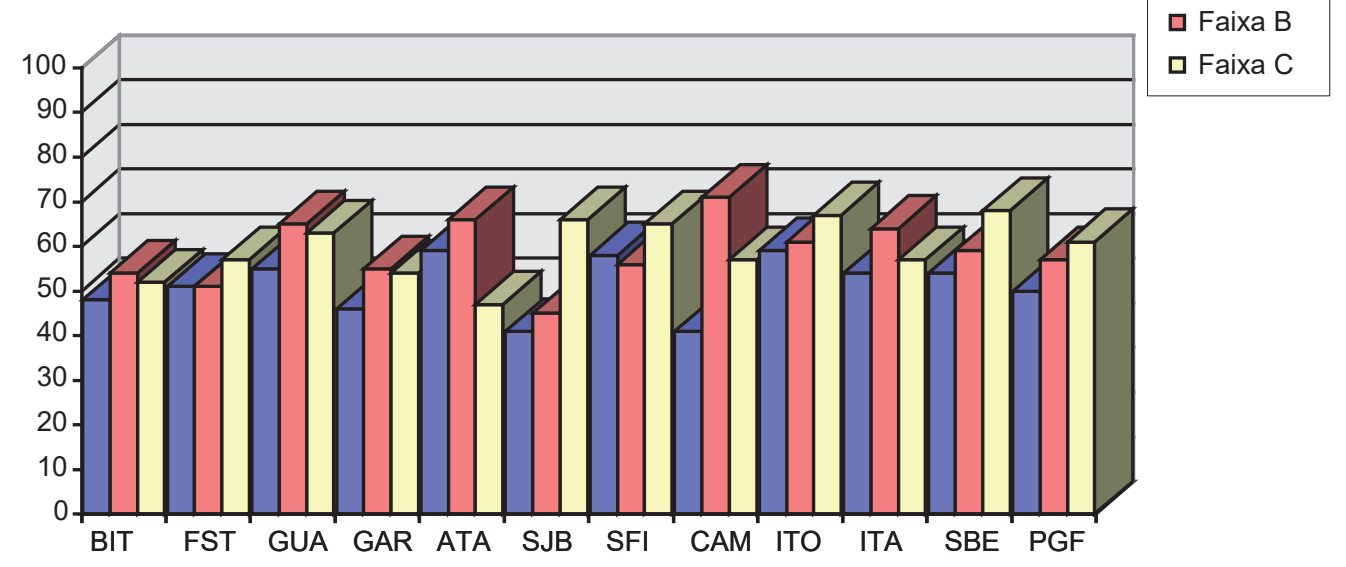

Gráfico 6 Índices percentuais referentes ao cruzamento das variáveis faixa etária e localidade. (Valor de aplicação: cancelamento).

Os resultados referentes à variável localidade mostraram que, em Barra de Itabapoana, ocorre o menor índice de cancelamento (.29), e nas localidades de Guaxindiba, Ponta Grossa dos Fidalgos, Itaocara, São Benedito e São Fidélis, encontram-se os índices mais elevados. Para uma análise mais abrangente, decompôs-se a variável, segundo o ambiente natural em que se desenvolve a atividade pesqueira: rio, lagoa ou mar, e localidades interioranas versus litorâneas. As localidades de pesca fluvial apresentaram o maior índice de aplicação da regra de cancelamento (.64); já as de pesca marítima, a de concordância (.44). No confronto entre as localidades litorâneas e interioranas, são estas últimas que mostraram níveis mais elevados de cancelamento (.55).

Tabela 6 Índices referentes à variável localidade. (Valor de aplicação: cancelamento).

\begin{tabular}{|l|c|c|c|c|}
\hline \multicolumn{1}{|c|}{ LOCALIDADE } & OCO & $\%$ & P. R.N.1 & P. R.N.S \\
\hline Barra de Itabapoana & $214 / 414$ & $52 \%$ & .46 & .29 \\
\hline Farol de São Tomé & $244 / 460$ & $53 \%$ & .47 & .38 \\
\hline Guaxindiba & $177 / 290$ & $61 \%$ & .55 & .67 \\
\hline
\end{tabular}




\begin{tabular}{|l|c|c|c|c|}
\hline Gargaú & $213 / 412$ & $52 \%$ & .46 & .37 \\
\hline Atafona & $272 / 482$ & $56 \%$ & .51 & .54 \\
\hline São João da Barra & $191 / 404$ & $47 \%$ & .42 & .33 \\
\hline São Fidélis & $262 / 437$ & $60 \%$ & .54 & .62 \\
\hline Cambuci & $211 / 386$ & $55 \%$ & .49 & .40 \\
\hline Itaocara & $240 / 387$ & $62 \%$ & .56 & .64 \\
\hline Itaperuna & $192 / 332$ & $58 \%$ & .52 & .57 \\
\hline São Benedito & $227 / 375$ & $61 \%$ & .55 & .63 \\
\hline Ponta Grossa dos Fidalgos & $227 / 405$ & $56 \%$ & .50 & .65 \\
\hline
\end{tabular}



Gráfico 7 Pesos relativos referentes à variável localidade. (Valor de aplicação: cancelamento).

A variável auxiliar escolaridade, apesar de ter sido selecionada, não pôde ser considerada para o condicionamento da regra de cancelamento, em virtude de não ter sido sistematicamente controlada.

A variável contexto fonológico subsequente não se apresentou relevante para o fenômeno em questão, pois foi sistematicamente descartada pelo programa. Os resultados referentes ao nível 1 mostram que o contexto mais favorável ao cancelamento da marca é a pausa, enquanto os contextos de vogal e consoante apresentaram diferença mínima. 
Com o objetivo de se investigar o efeito da variável, procedeu-se a análises em que se levaram em conta as variáveis estatisticamente relevantes, todos os grupos de fatores em cada localidade e cada faixa etária isolada. Em linhas gerais, pode-se afirmar que a variável cumpriu a função de auxiliar na análise das variáveis sociais. Os resultados mostram, entretanto, que a distribuição irregular dos dados dos informantes analfabetos e escolarizados pelas localidades e faixas etárias pode ter contribuído para que o programa selecionasse as variáveis sociais entre as representativas.

\section{CONCLUSÃO}

O presente estudo demonstrou que a tendência à aplicação da regra de cancelamento da marca de número nos constituintes do SN é condicionada, sobretudo, por fatores de natureza estrutural: (1) a variável relação entre os constituintes do $S N$ demonstrou que o cancelamento é mais produtivo entre os elementos pospostos ao núcleo e nos elementos nucleares na $2^{a}$ posição: nos elementos pré-nucleares, a presença de marca é praticamente categórica; (2) a variável marcas precedentes permitiu verificar que, se um constituintes do SN é precedido por outro com marca formal de plural ou com marca semântica, é grande a tendência ao cancelamento da marca no elemento nuclear; (3) o princípio do paralelismo formal mostrou-se relevante entre os elementos pré-nucleares, nos quais se inserem os determinantes. Com o corpus em que se baseia este estudo é formado majoritariamente por SNs constituídos por dois elementos, é possível dizer que, nesse caso, estaria ocorrendo o Princípio da Economia Linguística; (4) os vocábulos que menos se diferenciaram fonicamente são os mais propensos ao cancelamento da marca de número, enquanto os terminados em /S/ no singular aparecem como os mais propícios à presença de marca; (5) no que tange à tonicidade, os itens proparoxítonos são os mais propensos ao cancelamento, enquanto os monossílabos tônicos e oxítonos apresentam maior possibilidade de retenção da marca; (6) para a regra de cancelamento, não se mostrou relevante o contexto fonológico subsequente; (7) a tendência ao cancelamento da marca de número predomina na fala dos pescadores mais velhos (faixas B e C), sendo menos significativa na faixa dos mais jovens (faixa A). Tal tendência talvez se deva a fatores sócio-comportamentais peculiares às comunidades pesqueiras, entre as quais devem ser investigadas em profundidade a maior ou menor interação com falantes de outras regiões e/ou classes sociais; (8) o cancelamento da marca de número mostrou-se mais significativo nas localidades de Guaxindiba, Ponta Grossa dos Fidalgos, Itaocara, São Benedito e São Fidélis, o que pode ser resultado de influências sócio-histórico-culturais que as ainda parcas informações sobre a região - a menos conhecida do Estado - não permitem ainda determinar. 
Os resultados da pesquisa confirmam e complementam os que se expõem nos trabalhos de Scherre, bem como em outros, de cunho variacionista, sobre o tema, constituindo mais uma contribuição para o conhecimento do Português falado no Brasil, em especial na sua variante popular.

\section{REFERÊNCIAS BIBLIOGRÁFICAS}

ALMEIDA, Evanilda Marins. A variação da concordância nominal num dialeto rural. Dissertação (Mestrado em Letras Vernáculas) - Faculdade de Letras, Universidade Federal Rio de Janeiro, 1997.

SCHERRE, Maria Marta Pereira. Reanálise da concordância nominal em Português. 2 v. Tese (Doutorado em Letras Vernáculas) - Faculdade de Letras, Universidade Federal do Rio de Janeiro, Rio de Janeiro, 1988. 